\title{
PENGEMBANGAN PAPAN PEREDAM BUNYI MELALUI MODIFIKASI NANO SILIKAT AMPAS TEBU PG KREMBOENG DENGAN TEMPLATE SERAT SABUT KELAPA
}

\author{
Hengky Herdianto ${ }^{1}$, M. Alfi Zahwanul Farich ${ }^{2}$ \\ 1) Jurusan Fisika FMIPA Universitas Negeri Surabaya \\ 2) Jurusan Teknik Mesin Fakultas Teknik Universitas Negeri Surabaya \\ email : hengky_herdianto_sains_club@yahoo.com
}

\begin{abstract}
Abstrak
Manusia memiliki batas kemampuan mendengar suara pada rentang hingga $140 \mathrm{~dB}$, lebih daripada itu akan terjadi kerusakan pada organ-organ dalam gendang telinga. Ampas tebu PG Kremboeng mengandung 70,97\% silikat murni yang berpotensi memberikan penguatan pada papan serat dan meningkatkan performa serap bunyi. Metode yang digunakan untuk sintesis nano silikat ampas tebu dilakukan dengan cara Pretreatment BBA, tukar kation silikat, dan pencucian gel kering. Komponen silikat dan produk lain dalam ampas tebu ditentukan menggunakan difraksi sinar-X(XRD). Morfologi xerogels nano silikat dan papan serat telah diteliti dengan menggunakan Scanning Electron Microscopy (SEM). Daya serap ditentukan dari berat sebelum dan sesudah perendaman dalam air 24 jam. Pengujian keteguhan patah dan Modulus of Elasticity dilakukan dengan Universal Testing Machine. Uji Internal Bond direkatkan pada dua buah blok alumunium dengan perekat besi dan dibiarkan mengering. Koefisien serap diukur dengan sound level meter. Berdasarkan pola XRD, dapat diketahui bahwa terdeteksi medium silicate hydroxide. Berdasarkan mikrograf SEM dapat diketahui suatu struktur bongkahan yang memanjang halus terdiri atas kumpulan-kumpulan partikel nano silikat pada papan dengan template serat sabut kelapa. Sampel terbaik dalam penelitian ini adalah I (60\%;17\%;23\%) dengan nilai DSA 82,38\%, MOR 102,84 kg/ $\mathrm{cm}^{2}$, MOE $11.228,52 \mathrm{~kg} / \mathrm{cm}^{2}$, dan IB $0,83 \mathrm{~kg} / \mathrm{cm}^{2}$. Interval nilai koofisien serap taraf intensitas bunyi antar sampel adalah $0,527 \leq$ $x \leq 1,000$ pada pagi hari, $0,544 \leq x \leq 1,000$ pada siang hari, dan 0,538 $\leq x \leq 1,000$ pada malam hari. Sehingga secara keseluruhan interval pada segala kondisi waktu adalah $0,527 \leq x \leq 1,000$.
\end{abstract}

Kata kunci : Papan, Bunyi, Nano Silikat, Ampas Tebu, Sabut Kelapa.

\begin{abstract}
Human have auditory limit until $140 \mathrm{~dB}$. An internal hearing organ damage can exist if they hear sound more than that. The bagasse in PG Kremboeng contained $70.97 \%$ of pure silicate which was able to strengthen the fiber board and increase the sound absorber. The methods to synthesize silicate nano of bagasse was by using BBA pretreatment, exchanging silicate cation, and washing dry gel. Silicate component and other products in sugar cane residue were determined by using $X$-ray diffraction (XRD). Xerogels morphology of silicate nano and fiber board had been examined by using Scanning Electron Microscopy (SEM). The absorb ability was determined from before and after dyeing mass in water for 24 hours. The fracture testing and modulus of elasticity were held by using universal testing machine. The internal bond testing was glued onto two aluminum blocks with iron as the glue and let it dry. A sound level meter was used to measure the absorber coefficient. According to XRD pattern, the hydroxide silicate medium could be seen, while SEM micrograph detected a long soft chunks structure contained sets of silicate nano particles in the board with coconut fiber template. The best sample in this research project was I (60\%;17\%;23\%) with DSA 82,38\%, MOR $102,84 \mathrm{~kg} / \mathrm{cm}^{2}$, MOE $11.228,52 \mathrm{~kg} / \mathrm{cm}^{2}$, and IB $0,83 \mathrm{~kg} / \mathrm{cm}^{2}$. The interval of absorber coefficient for $\mathrm{s}$ rate sound intensity was $0,527 \leq x \leq 1,000$ in the morning, 0,544 $\leq x \leq 1,000$ in the midday, and $0,538 \leq x \leq 1,000$ in the night, therefore the overall interval in all condition was $0,527 \leq x \leq 1,000$.
\end{abstract}

Keywords: Board, Sound, Silicate nano, Bagasse, Coconut fiber 


\section{PENDAHULUAN}

Masyarakat wilayah perkotaan rentan terpapar polusi suara. Manusia memiliki batas kemampuan mendengar suara mulai dari 20 hingga 20.000 hertz atau setara dengan rentang hingga 140 desibel. Lebih dari itu, akan terjadi kerusakan pada gendang telinga dan organ-organ lain dalam gendang telinga $[5,6]$. Hasil studi epidemologis di Amerika Serikat menyebutkan, ketidakstabilan emosi akibat terpapar suara bising akan menyebabkan stres. Jika ditambah dengan penyempitan pembuluh darah, maka dapat memacu jantung untuk bekerja lebih keras memompa darah ke seluruh tubuh sehingga mengakibatkan hipertensi [6].

Penelitian sebelumnya telah dipaparkan sebuah inovasi Komposit Sabut Kelapa dan Resin sebagai peredam bunyi, hasil penelitian menunjukkan bahwa interval nilai koofisien serap taraf intensitas bunyi antar sampel adalah $0,408 \leq x \leq 0,891$. Pada interval tersebut dapat dinyatakan kurang maksimal dalam memberikan perlindungan terhadap polusi suara.

Penggunaan sintesis Nano Silikat ampas tebu sebagai bahan penguat dan peningkat mutu koofisien serap taraf intensitas bunyi dalam penelitian ini dikarenakan berdasarkan hasil analisis No 4246/LT AKI/XI/99 oleh Tim Afiliansi dan Konsultasi Industri ITS Surabaya, ampas tebu mengandung $70,97 \%$ kandungan silikat murni yang berpotensi memberikan penguatan pada papan serat komposit dan meningkatkan peforma sifat fisis adiabatis pada fluida gas gelombang bunyi $[2,3]$.

Tujuan penelitian ini: 1) Mendiskripsikan pengaruh perbandingan komposisi material sampel terhadap koofisien serap taraf intensitas bunyi pada komposit hasil modifikasi nano silikat pada ampas tebu dengan template pulp serat sabut kelapa; 2) Menentukan interval nilai koofisien komposit peredam bunyi hasil modifikasi nano silikat pada ampas tebu dengan template pulp serat sabut kelapa.

\section{Ampas Tebu}

Ampas tebu merupakan hasil samping dari proses ekstraksi cairan tebu. Dari satu pabrik dapat dihasilkan sekitar 35-40\% dari berat tebu yang digiling. Ampas tebu mengandung air $48-52 \%$, gula $2,5-6 \%$, dan serat 44-48\% [8].

Tabel 1. Komponen Penyusun Sabut

\begin{tabular}{|c|c|c|c|c|}
\hline \multirow{2}{*}{$\begin{array}{c}\text { Materia } \\
\mathbf{l}\end{array}$} & \multicolumn{4}{|c|}{ Nama Bahan (\%) } \\
\cline { 2 - 5 } & $\begin{array}{c}\text { Selul } \\
\text { osa }\end{array}$ & $\begin{array}{c}\text { Pentos } \\
\text { an }\end{array}$ & $\begin{array}{c}\text { Lign } \\
\text { in }\end{array}$ & $\begin{array}{c}\text { Lai } \\
\text { n- } \\
\text { lain }\end{array}$ \\
\hline $\begin{array}{l}\text { Ampas } \\
\text { Tebu }\end{array}$ & 45 & 32 & 18 & 5 \\
\hline
\end{tabular}

Sumber: BPPT Mataram, 2002; Penebar Swadaya, 2000

Tabel 2. Komposisi Unsur Kimia Ampas Tebu

\begin{tabular}{|l|c|c|c|c|}
\hline & \multicolumn{4}{|c|}{ Kandungan (\%) } \\
\hline $\begin{array}{c}\text { Peneliti } \\
\text { an }\end{array}$ & $\begin{array}{c}\text { Karb } \\
\text { on }\end{array}$ & $\begin{array}{c}\text { Hidrog } \\
\text { en }\end{array}$ & $\begin{array}{c}\text { Oksig } \\
\text { en }\end{array}$ & $\begin{array}{c}\text { As } \\
\text { h }\end{array}$ \\
\hline N. Deer & 46,5 & 6,5 & 46,0 & 1,0 \\
\hline Tromp & 44,0 & 6,0 & 48,0 & 2,0 \\
\hline Kelly & 48,2 & 6,1 & 44,4 & 2,0 \\
\hline M.R & 47,5 & 6,1 & 44,4 & 2,0 \\
\hline Daries & 47,9 & 6,7 & 45,5 & - \\
\hline Gregory & 48,1 & 6,1 & 43,3 & 2,5 \\
\hline
\end{tabular}

Sumber: Daulay, 2010; Penebar Swadaya, 2000

Tabel 3. Senyawa Kimia dalam Ampas Tebu

\begin{tabular}{|l|c|}
\hline Senyawa Kimia & Jumlah (\%) \\
\hline $\mathrm{SiO}_{2}$ & 70,97 \\
\hline $\mathrm{Al}_{2} \mathrm{O}_{3}$ & 0,33 \\
\hline $\mathrm{Fe}_{2} \mathrm{O}_{3}$ & 0,36 \\
\hline
\end{tabular}




\begin{tabular}{|l|c|}
\hline $\mathrm{K}_{2} \mathrm{O}$ & 4,82 \\
\hline $\mathrm{Na}_{2} \mathrm{O}$ & 0,43 \\
\hline $\mathrm{MgO}$ & 0,82 \\
\hline $\mathrm{C}_{5} \mathrm{H}_{10} \mathrm{O}_{5}$ & 22,27 \\
\hline
\end{tabular}

Sumber: BPPT Mataram, 2002; Penebar Swadaya, 2000

\section{Resin Matriks}

Monomer memiliki berat molekul lebih tinggi dari pada metilmetakrilat dapat membantu mengurangi pengerutan polimerisasi. Nilai polimerisasi pengerutan untuk resin metil metakrilat adalah $22 \% \mathrm{~V}$ dimana untuk resin Bis-GMA 7,5\%V. BisGMA dan UDMA merupakan cairan yang memiliki kekentalan tinggi karena memiliki berat molekul yang tinggi. Untuk mengatasi masalah tersebut, monomer yang memiliki kekentalan rendah yang dikenal sebagai pengontrol kekentalan ditambahkan seperti metil metkrilat (MMA), etilen glikol dimetakrilat (EDMA), dan trietilen glikol dimetakrilat (TEGDMA) adalah yang paling sering digunakan [7].

\section{METODE PENELITIAN}

Jenis penelitian ini adalah true experiment design kuantitatif dengan sampel komposit sabut kelapa yang telah dikembangkan dengan modifikasi nano silikat hasil sintesis ampas tebu.

\section{Sintesis Nano Silikat Ampas Tebu}

Metode yang digunakan untuk sintesis nano silikat ampas tebu: 1) Pretreatment BBA menggunakan cuci asam; 2) Pengobatan resin natrium menggunakan tukar kation silikat; dan 3) Mencuci gel kering menggunakan air demineralisasi. Silika diekstraksi dari 10 gram BBA, menggunakan ml 60 dari $2 \mathrm{M} \mathrm{NaOH}$ untuk memproduksi natrium silikat. Dalam metode 1, BBA dicuci menggunakan pengobatan asam. Selama ekstraksi silika, campuran abu ampas tebu dan larutan
$\mathrm{NaOH}$ direbus selama 1 jam dengan pengadukan konstan [1].

\section{Karakterisasi}

Isi silika dan komponen lain dalam ampas tebu dan produk ditentukan menggunakan difraksi sinar-X (XRD) (RINT 2200V, Rigaku-Denki Corp., Tokyo, Japan) analisis yang digunakan untuk mendapatkan informasi tentang struktur kristalografi xerogels nano silika. Selain itu, morfologi xerogels nano silika telah diteliti dengan menggunakan Scanning Electron Microscopy (SEM) (S5000, Hitachi Ltd., Tokyo, Japan).

\section{Pembuatan Komposit}

Pada penelitian sintesis komposit langkah-langkah yang dilakukan adalah sebagai berikut: $\quad$ 1) Sabut kelapa di pisahkan bagian-bagiannya menjadi daging sabut (Cocopeat) dan serat sabut (Cocofiber) dengan menggaruknya memakai sikat diatas talenan; 2) Memodifikasi Nano silikat ampas tebu yang telah disintesis; 3) Setelah komposisi sampel di buat bahan di campur dan di aduk di dalam baskom, kemudian dicetak (dipres) dengan tekanan dan selang waktu tertentu dan dikeringkan dengan furnace pada suhu $120^{\circ} \mathrm{C}$.

\section{Uji Karakteristik Fisis dan Mekanis}

Daya serap dihitung dari berat sebelum dan sesudah perendaman dalam air 24 jam pada contoh uji dengan rumus $[4,7]$ :

$$
D S A=\frac{B_{2}-B_{1}}{B_{1}} \times 100 \%
$$

Dimana DSA: daya serap air (\%), $B_{1}$ : berat contoh uji sebelum perendaman (gram), dan

$B_{2}$ : berat contoh uji setelah perendaman (gram)

Pengujian keteguhan patah dilakukan dengan Universal Testing Machine dengan menggunakan lebar bentang 14 kali tebal, tetapi tidak kurang dari $14 \mathrm{~cm}$. Nilai $M O R$ dihitung dengan menggunakan rumus $[4,7]$ : 


$$
M O R=\frac{3 P L}{2 b d^{2}}
$$

Dimana MOR: modulus patah $\left(\mathrm{kg} / \mathrm{cm}^{2}\right)$, $P$ : beban maksimum $(\mathrm{kg}), L$ : jarak sangga (cm), $b$ : tebal dan lebar contoh uji (cm), dan $d$ : tebal contoh uji (cm).

Pengujian MOE dilakukan bersamasama dengan pengujian keteguhan patah dengan memakai contoh uji yang sama. Besarnya defleksi yang terjadi pada saat pengujian dicatat pada setiap selang beban tertentu. Nilai $M O E$ dihitung dengan rumus $[4,7]$ :

$$
M O E=\frac{\Delta P L^{3}}{4 \Delta Y b d^{3}}
$$

Dimana MOE: modulus lentur $\left(\mathrm{kg} / \mathrm{cm}^{2}\right)$, $\Delta P$ : beban sebelum batas proporsi $(\mathrm{kg}), L$ : jarak sangga $(\mathrm{cm}), \Delta Y$ : lenturan pada beban (cm), $b$ : lebar contoh uji (cm), dan $d$ : tebal contoh uji $(\mathrm{cm})$.

Pengujian $I B$, contoh uji direkatkan pada dua buah blok alumunium dengan perekat besi dan dibiarkan mongering. Kedua blok ditarik tegak lurus permukaan contoh uji sampai beban maksimum. Pengujian keteguhan rekat dihitung dengan rumus $[4,7]$ :

$$
I B=\frac{P_{\max }}{A}
$$

Dimana $I B$ : keteguhan rekat internal $\left(\mathrm{kg} / \mathrm{cm}^{2}\right), P_{\text {max }}$ : beban maksimum $(\mathrm{kg})$, dan $A$ : luas permukaan contoh $\left(\mathrm{cm}^{2}\right)$.

\section{Uji Koefisien Absorbsi Bunyi}

Koefisien serap (absorpsi) adalah angka tanpa satuan yang menunjukkan perbandingan antara energi bunyi yang diserap oleh material pembatas berbanding keseluruhan energi bunyi yang mengenai material pembatas. Koefisien redam bunyi dapat dihitung dengan persamaan menurut Giancoli (2010) sebagai berikut [4,7]:

$$
\alpha=\frac{I}{I_{o}}
$$

Dimana $\alpha$ : Koofisien serap intensitas bunyi, $I$ : Intensitas bunyi yang diserap (db), dan $I_{o}$ : Intensitas bunyi sebelum lewat bahan $(\mathrm{db})$.

\section{HASIL DAN PEMBAHASAN}

\section{Karakterisasi Isi dan Morfologi Komposit}

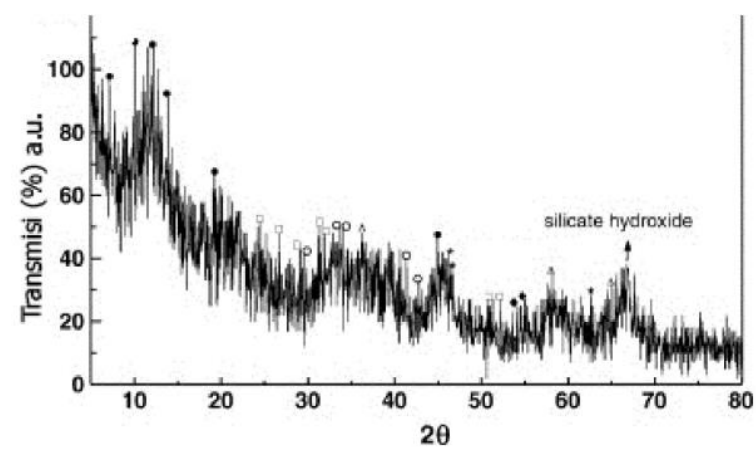

Gambar 1. Pola XRD Komposit Modifikasi

Pada Gambar 1 terlihat pola XRD dari komposit modifikasi nano silikat pada ampas tebu dengan template pulp serat sabut kelapa pada temperatur $900^{\circ} \mathrm{C}$. Berdasarkan pola $X R D$ tersebut, dapat diketahui bahwa terdeteksi silicate hydroxide. Berdasarkan mikrograf SEM yang dihasilkan, dapat diketahui bahwa mikrostruktur yang terbentuk memperlihatkan suatu struktur bongkahan yang memanjang halus terdiri atas kumpulan-kumpulan partikel nano silikat pada komposit modifikasi, pola memanjang ini mengikuti pola dari template pulp sabut kelapa. Bentuk mikrostruktur yang memanjang halus ini kemungkinan diakibatkan oleh proses penghalusan pulp dengan menggunakan ultra turrax pada kecepatan $10.000 \mathrm{rpm}$ di dalam larutan prekursor. 

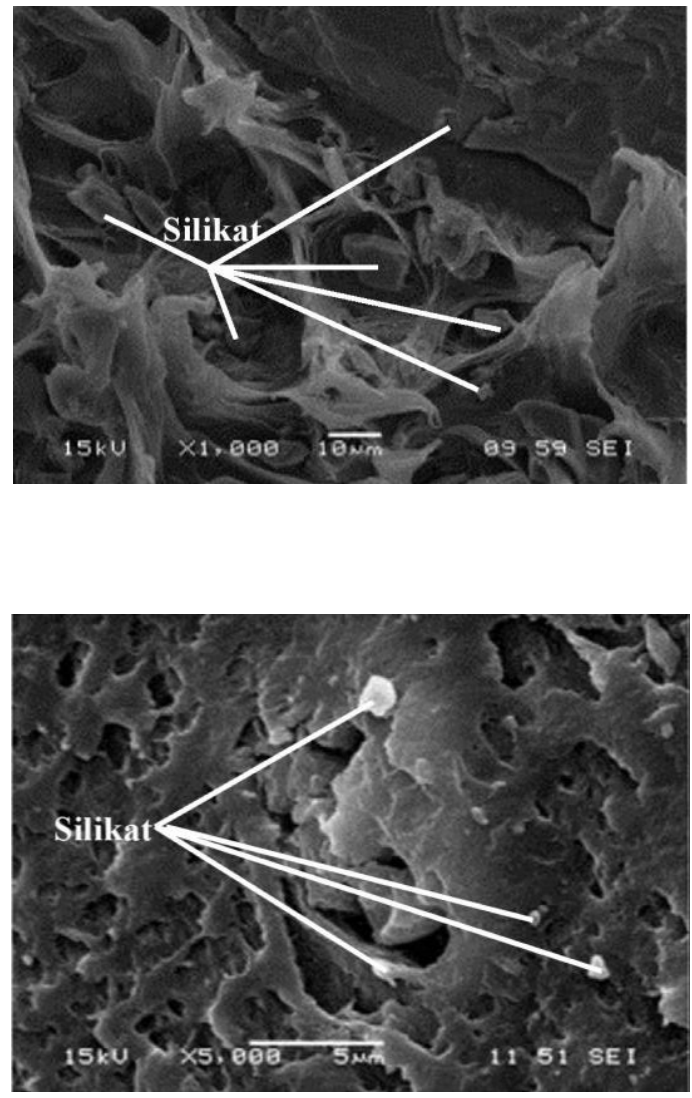

Gambar 2. SEM Komposit pada Pusat Sabut Kelapa

Dari Gambar 2, di atas dapat diketahui morfologi komposit hasil modifikasi pada pusat distribusi komposit sabut kelapa telah tampak bahwa nanopartikel silikat telah tersebar dengan merata pada tiap titik serat sabut kelapa. Sehingga dalam hal ini kinerja nanopartikel silikat dapat memberikan kontribusi penuh, karena distribusinya yang merata pada tiap titik. Bantuk nanopartikel silikat adalah butirbutir halus dengan ukuran 20-45 nm.

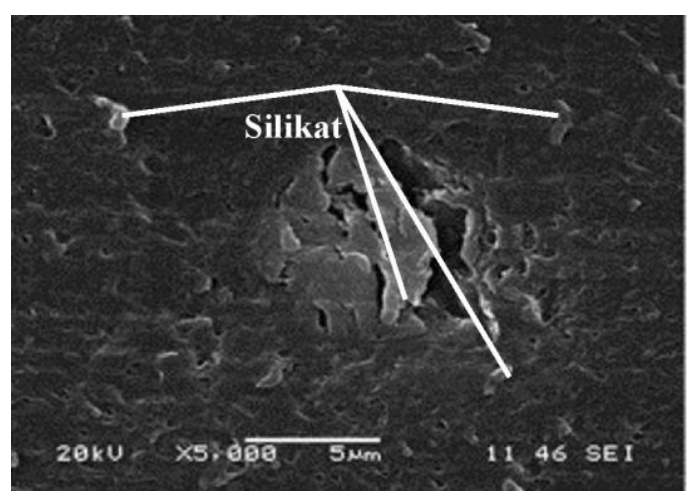

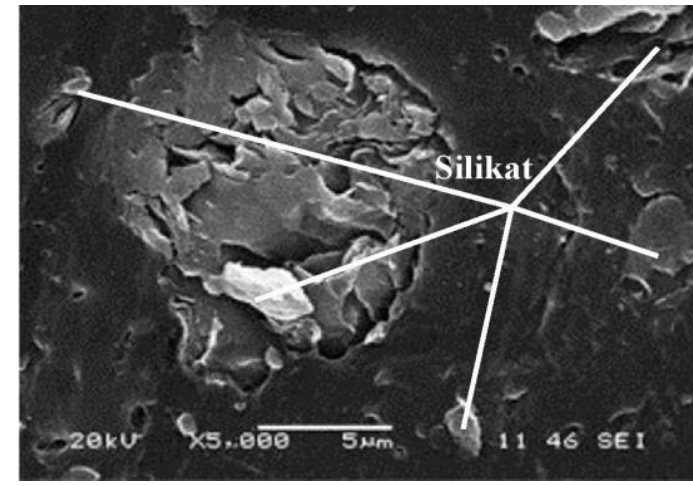

Gambar 3. SEM Komposit pada Tepi Komposit

Dari Gambar 3, dipaparkan morfologi komposit hasil modifikasi pada bagian tepi komposit yang sedikit terdapat komponen sabut kelapa, telah tampak bahwa nanopartikel silikat telah tersebar dengan merata pada tiap titik resin fiber glass. Namun distribusinya tidak begitu merata hanya terpusat pada bagian tepi komposit. Sehingga dalam hal ini kinerja nanopartikel silikat dapat memberikan kontribusi penuh dalam mempertahankan bentuk bangun komposit, karena distribusinya yang merata pada tiap tepi. Bantuk nanopartikel silikat adalah butir-butir halus dengan ukuran 15$50 \mathrm{~nm}$.

\section{Karakteristik Fisis dan Mekanis}

Tabel 4. Nilai Uji Karakteristik Fisis dan Mekanis

\begin{tabular}{|l|c|c|c|c|}
\hline Sampel & $\begin{array}{c}\text { DSA } \\
(\%)\end{array}$ & $\begin{array}{c}\text { MOR } \\
(\mathbf{k g} / \mathbf{c} \\
\left.\mathbf{m}^{2}\right)\end{array}$ & $\begin{array}{c}\text { MOE } \\
\left(\mathbf{k g} / \mathbf{c m}^{2}\right.\end{array}$ & $\begin{array}{c}\text { IB } \\
(\mathbf{k g} / \mathbf{c} \\
\left.\mathbf{m}^{2}\right)\end{array}$ \\
\hline $\begin{array}{l}\text { A } \\
\text { 0:0:100 }\end{array}$ & 4,55 & 46,363 & $\begin{array}{c}4.471,25 \\
4\end{array}$ & 0,423 \\
\hline B 5:2:93 & 11,38 & 51,425 & $\begin{array}{c}4.873,82 \\
3\end{array}$ & 0,456 \\
\hline C & 15,88 & 57,395 & $5.827,54$ & 0,484 \\
$10: 4: 86$ & & & 8 & \\
\hline
\end{tabular}




\begin{tabular}{|c|c|c|c|c|}
\hline $\begin{array}{l}\text { D } \\
15: 6: 79\end{array}$ & 35,57 & 64,573 & $\begin{array}{c}6.337,74 \\
6\end{array}$ & 0,576 \\
\hline $\begin{array}{l}\text { E } \\
20: 8: 72\end{array}$ & 57,38 & 67,387 & $\begin{array}{c}6.692,25 \\
2\end{array}$ & 0,596 \\
\hline $\begin{array}{l}\mathrm{F} \\
30: 10: 6 \\
0\end{array}$ & 63,45 & 77,188 & $\begin{array}{c}7.782,26 \\
2\end{array}$ & 0,649 \\
\hline $\begin{array}{l}\text { G } \\
40: 12: 4 \\
8\end{array}$ & 72,24 & 84,684 & $\begin{array}{c}8.571,65 \\
8\end{array}$ & 0,766 \\
\hline $\begin{array}{l}\mathrm{H} \\
50: 14: 3 \\
6\end{array}$ & 81,65 & $\begin{array}{c}108,51 \\
8\end{array}$ & $\begin{array}{c}9.174,96 \\
8\end{array}$ & 0,845 \\
\hline $\begin{array}{l}\text { I } \\
60: 17: 2 \\
3\end{array}$ & 82,38 & $\begin{array}{c}102,84 \\
0\end{array}$ & $\begin{array}{c}11.228,5 \\
2\end{array}$ & 0,830 \\
\hline $\begin{array}{l}\mathbf{J} \\
70: 18: 1 \\
2\end{array}$ & 85,38 & $\begin{array}{c}120,46 \\
8\end{array}$ & $\begin{array}{c}11.374,5 \\
38\end{array}$ & 0,939 \\
\hline Rerata & 50,33 & 79,875 & $\begin{array}{c}7.493,76 \\
8\end{array}$ & 0,658 \\
\hline Min & 4,56 & 46,373 & $\begin{array}{c}4.472,28 \\
4\end{array}$ & 0,413 \\
\hline Max & 85,29 & $\begin{array}{c}121,45 \\
8\end{array}$ & $\begin{array}{c}11.373,5 \\
30\end{array}$ & 0,928 \\
\hline
\end{tabular}

Dari Tabel 4, di atas dapat diketahui bahwa hasil uji karakteristik fisis maupun mekanis komposit yang dimodifikasi memiliki 3 peringkat terbaik pada sampel H, I, dan J. Ketiga sampel tersebut memiliki perpaduan material yang proporsional sehingga direkomendasikan sebagai komposit terstandarisasi.
Nilai Koofisien Serap Intensitas Bunyi

Tabel 5. Nilai Koofisien Serap Taraf Inrensitas Bunyi

\begin{tabular}{|c|c|c|c|c|c|}
\hline \multirow{2}{*}{ Sampel } & \multirow{2}{*}{ K:A:R } & \multicolumn{4}{|c|}{$\alpha$} \\
\hline & & Pagi & $\begin{array}{c}\text { Sian } \\
\mathbf{g}\end{array}$ & $\begin{array}{c}\text { Mala } \\
\mathbf{m}\end{array}$ & $\begin{array}{c}\text { Rerat } \\
\mathbf{a}\end{array}$ \\
\hline \multirow[t]{2}{*}{ A } & 0:0:10 & 0,52 & 0,54 & & \\
\hline & 0 & 7 & 4 & 0,538 & 0,534 \\
\hline \multirow[t]{2}{*}{ B } & & 0,62 & 0,63 & & \\
\hline & $5: 2: 93$ & 5 & 7 & 0,626 & 0,625 \\
\hline \multirow[t]{2}{*}{$\mathrm{C}$} & $10: 4: 8$ & 0,66 & 0,68 & & \\
\hline & 6 & 7 & 6 & 0,645 & 0,658 \\
\hline \multirow[t]{2}{*}{ D } & $15: 6: 7$ & 0,76 & 0,74 & & \\
\hline & 9 & 3 & 9 & 0,757 & 0,746 \\
\hline \multirow[t]{2}{*}{$\mathrm{E}$} & $20: 8: 7$ & 0,81 & 0,81 & & \\
\hline & 2 & 4 & 6 & 0,788 & 0,821 \\
\hline \multirow[t]{2}{*}{$\mathrm{F}$} & 30:10: & 0,88 & 0,88 & & \\
\hline & 60 & 4 & 5 & 0,867 & 0,883 \\
\hline \multirow[t]{2}{*}{ G } & 40:12: & 1,00 & 1,00 & & \\
\hline & 48 & 0 & 0 & 1,000 & 1,000 \\
\hline \multirow[t]{2}{*}{$\mathrm{H}$} & 50:14: & 1,00 & 1,00 & & \\
\hline & 36 & 0 & 0 & 1,000 & 1,000 \\
\hline \multirow[t]{2}{*}{ I } & 60:17: & 1,00 & 1,00 & & \\
\hline & 23 & 0 & 0 & 1,000 & 1,000 \\
\hline \multirow[t]{2}{*}{$\mathrm{J}$} & 70:18: & 0,95 & 0,96 & & \\
\hline & 12 & 7 & 8 & 0,954 & 0,960 \\
\hline \multirow{2}{*}{\multicolumn{2}{|c|}{ Rerata }} & 0,82 & 0,83 & & \\
\hline & & 4 & 0 & 0,819 & 0,824 \\
\hline \multirow{2}{*}{\multicolumn{2}{|c|}{ Min }} & 0,52 & 0,54 & & \\
\hline & & 7 & 4 & 0,538 & 0,554 \\
\hline \multirow{2}{*}{\multicolumn{2}{|c|}{ Max }} & 1,00 & 1,00 & & \\
\hline & & 0 & 0 & 1,000 & 1,000 \\
\hline
\end{tabular}

Hasil penelitian nilai koofisien serap taraf intensitas bunyi menunjukkan bahwa sampel G, H, dan I mempunyai nilai tertinggi dengan nilai 1,000 pada pagi, 
siang, dan malam hari. Sampel G, H, dan I merupakan sampel terbaik dari semua sampel. Hal ini dikarenakan pada persentase material tersebut mampu memberikan daya ikat dan daya serap partikel fluida maupun gelombang bunyi maksimal. Sehingga taraf intensitas yang keluar melalui papan komposit dapat diminimalisir. Berbeda pada sampel kontrol hanya menggunakan resin tanpa sabut kelapa, gelombang yang masuk tanpa adanya hambatan dari partikel serat sabut kelapa.

Dari data di atas dapat diketahui bahwa interval nilai koofisien serap taraf intensitas bunyi antar sampel adalah 0,527 $\leq x \leq$ 1,000 pada pagi hari, $0,544 \leq x \leq 1,000$ pada siang hari, dan $0,538 \leq x \leq 1,000$ pada malam hari. Sehingga secara keseluruhan interval pada segala kondisi waktu adalah $0,527 \leq x \leq 1,000$.

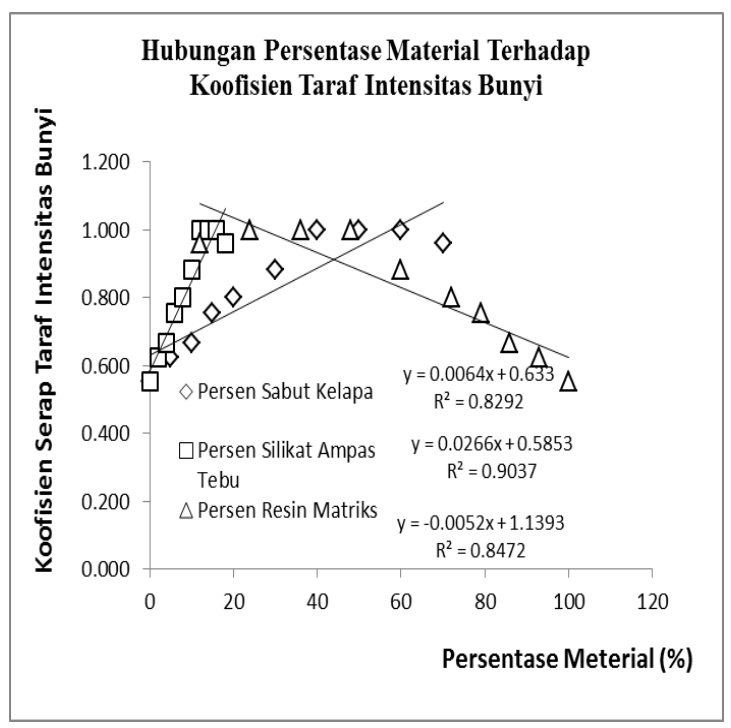

Gambar 4. Hubungan Persentase Metarial Terhadap Daya Redam Bunyi

Dari grafik di atas dapat dianalisis bahwa setiap persen sabut kelapa dan persen nano silikat ampas tebu bertambah atau meningkat dengan satu tingkatan pada komposit, maka rata-rata nilai koofisien serap taraf intensitas bunyi juga bertambah atau meningkat berturut-turut sebesar
0,0064 dan 0,0266 dengan taraf kelinearan $82,92 \%$ dan $90,37 \%$. Sedangkan setiap persen resin matriks yang ditambahkan tiap satu tingkat, maka rata-rata nilai koofisien serap taraf intensitas bunyi menurun dengan nilai 0,0052 dengan taraf kelinearan $84,72 \%$.

\section{KESIMPULAN}

Dari hasil pengujian dapat diambil kesimpulan bahwa:

1. Setiap persen sabut kelapa dan persen nano silikat ampas tebu bertambah dengan satu tingkatan pada komposit, maka rata-rata nilai koofisien serap taraf intensitas bunyi juga bertambah berturut-turut sebesar 0,0064 dan 0,0266 . Sedangkan setiap persen resin matriks yang ditambahkan tiap satu tingkat, maka rata-rata nilai koofisien serap taraf intensitas bunyi menurun dengan nilai 0,0052. Sampel terbaik dalam penelitian ini adalah I dengan komposisi $60 \%$ sabut kelapa, $17 \%$ nano silikat ampas tebu, dan $23 \%$ resin matriks.

2. Interval nilai koofisien serap taraf intensitas bunyi antar sampel adalah $0,527 \leq x \leq 1,000$ pada pagi hari, 0,544 $\leq x \leq 1,000$ pada siang hari, dan 0,538 $\leq x \leq 1,000$ pada malam hari. Sehingga secara keseluruhan interval pada segala kondisi waktu adalah $0,527 \leq x \leq 1,000$.

\section{DAFTAR PUSTAKA}

[1] Affandi, Samsudin et al. 2009. A Facile Method for Production of High-Purity Silica Xerogels from Bagasse Ash. Published by Elsevier B.V. and The Society of Powder Technology japan: 20 (2009) 468-472

[2] BPPPT Gula Putih Mataram. 2002. Hasil Analisis Baggase, Blotong, dan Abu. Lampung: PT Gula Putih Mataram

[3] Daulay, SHNS. 2010. Penggunaan Serat Limbah Ampas Tebu. [Serial Online]. http://repository.usu.ac.id/bitstream/123 
456789/19895/.../Chapter\%20II.pdf. [29 Maret 2012]

[4] FAO. 1997. Fiberboard and Particle Board. FAO: Genewa

[5] Koran SI. 2012. Waspadai Polusi Suara. [serial inline]. http://lifestyle.okezone.com/read/2012/ 09/16/27/372563/waspada-polusi-suara. [2 Januari 2012]

[6] Lembaga Kajian Pembangunan Kesehatan (LKPK). 2008. Polusi Suara, Ada Namun Terlupakan. [serial online]. http://lkpkindonesia.blogspot.com/2007/03/polusisuara-ada-namun-terlupakan.html. $\quad$ [4 Mei 2012]

[7] Malonay, T. M. 1977. Modern Particle Board and Dry Process Fiberboard Manufacturing. San Fransisco: Miller Freeman Inc

[8] Penebar 2000. Pembudidayaan Tebu di Lahan Sawah dan Tegalan. Jakarta: Penebar Swadaya 